\title{
Caracterização do sistema de produção em propriedades leiteiras de economia familiar em Presidente Olegário - MG: Fase Cria de Fêmeas
}

\author{
[Characterization of Calf Rearing in Family-Owned Dairy Farms in \\ Presidente Olegário - Minas Gerais]
}

\section{"Artigo Científico/Scientific Article"}

\author{
José dos Reis Pereira ${ }^{1}$, Gercílio Alves de Almeida Júnior ${ }^{2}$, Marcos Aurélio Lopes ${ }^{3 *}$, \\ Juliana Aparecida Vieira ${ }^{4}$, Alessandro Botelho Pereira ${ }^{5}$
}

\author{
${ }^{1}$ Empresa de Assistência Técnica e Extensão Rural, EMATER, Presidente Olegário-MG, Brasil. \\ ${ }^{2}$ Departamento de Zootecnia, Universidade Federal do Espírito Santo, Alegre-ES, Brasil. \\ ${ }^{3}$ Departamento de Medicina Veterinária, Universidade Federal de Lavras, Lavras-MG, Brasil. \\ ${ }^{4}$ Departamento de Zootecnia, Universidade Federal de Lavras, Lavras-MG, Brasil. \\ ${ }^{5}$ Empresa de Pesquisa Agropecuária de Minas Gerais, EPAMIG, Lavras-MG, Brasil. \\ Autor para correspondência/Corresponding author: E-mail: malopes@ dmv.ufla.br
}

\section{Resumo}

Objetivou-se, com este estudo, caracterizar propriedades produtoras de leite, em economia familiar, no que diz respeito a aspectos relacionados à cria de fêmeas de reposição. Os dados foram provenientes de 12 propriedades, localizadas na região Noroeste de Minas Gerais, no município de Presidente Olegário; no período entre maio e junho de 2016. Os dados foram cadastrados em planilhas do software Sphinx ${ }^{\circledR}$ e as respostas agrupadas por meio de sua categorização e frequência. Os dados evidenciaram que as falhas no manejo da fase de cria se iniciam no cuidado com as vacas no pré-parto e se estendem até a desmama das bezerras; e essa combinação de falhas deverá afetar a eficiência da atividade leiteira. Na maioria das propriedades as instalações são inadequadas ou mal localizadas. A maioria dos produtores faz a cria das bezerras em piquetes coletivos e não usa critérios para o agrupamento, manejando conjuntamente machos e fêmeas de várias idades e, assim, prejudicando o desempenho individual. A alimentação é feita sem critério na maioria das propriedades, o que pode estar contribuindo para o aumento da ocorrência dos problemas sanitários relatados. Não há adoção de protocolo sanitário específico para as bezerras e a falta de cuidados profiláticos básicos expõe os animais a maiores incidências de doenças e desvia o foco do cuidado sanitário para o tratamento de animais doentes ao invés da prevenção das mesmas. As possibilidades de viabilização técnica e econômica da pecuária familiar se tornam menores face às limitações observadas na fase de cria.

Palavras-chave: atividade leiteira; criação de bezerras; fêmeas de reposição.

\begin{abstract}
The objective of this study was to characterize family-owned dairy farms regarding aspects related to the rearing of calves. The data came from twelve farms, located in the Northwest region of Minas Gerais, in the municipality of Presidente Olegário; in the period between May and June 2016. The data were recorded in Sphinx ${ }^{\circledR}$ software spreadsheets and the answers were grouped by means of their categorization and frequency. The data evidenced that several failures in the management of the calves during the rearing phase start in the care of pre-calving cows and extend until the weaning of the calves, and this combination of failures should affect the efficiency of the business. In most of the properties, facilities are inadequate or poorly located. Most of the farmers raise calves in collective padocks and do not use criteria for grouping, jointly managing males and females of various ages and thus impairing their individual performance. Feeding is done without criteria in most of the properties, which may be contributing to the increase in occurrence of several reported sanitary problems. There is no adoption of a specific health protocol for heifers and the lack of basic prophylactic care exposes animals to a higher incidence of diseases and diverts the focus of health care to the treatment of sick animals rather than the prevention of the diseases. The possibilities of technical and economic feasibility for family farming become smaller in view of the limitations observed in the rearing phase.
\end{abstract}

Keywords: calf breeding; dairy business; replacement females. 


\section{Introdução}

A atividade leiteira, nos últimos anos, passou por grandes avanços. No entanto, apesar desse desenvolvimento, a criação de bezerras ainda é uma fase crítica com grandes riscos e alta mortalidade de animais (Silva e Hickmann, 2011). $\mathrm{O}$ sucesso dessa fase depende de um adequado sistema de criação, com alimentação e manejo adequados associados à redução de custo de produção desde o nascimento. Fato também destacado por Lopes e Santos (2014), ao afirmarem que a criação de bezerras para a reposição tem peso significativo no custo de produção do leite, representando a segunda maior fonte de despesas da atividade.

A fase de cria não tem recebido a atenção necessária por muitos produtores de leite, uma vez que, além de não gerar renda imediata, esta categoria animal representa despesas. No entanto, o produtor deveria se preocupar com o manejo das bezerras com o intuito de melhorar geneticamente seu rebanho com animais de maior potencial para produção de leite (Campos, 2012). Não obstante, sistemas inadequados de criação de bezerras causam prejuízos, pela perda de animais, ou mesmo pelos gastos com medicamentos. Esse problema se torna mais evidente em propriedades familiares, em geral, onde há grandes limitações no manejo das fases de cria e recria das fêmeas de reposição, o que comumente resulta em baixo desempenho zootécnico e econômico. Desta forma, a boa criação e o bom manejo das bezerras continuam sendo desafios a serem superados.

O município de Presidente Olegário - MG, tem na bovinocultura de leite uma das suas principais atividades econômicas, sendo essa a mais importante na geração de emprego e renda e exercendo, consequentemente, papel de grande importância social e ambiental. Dos produtores, $70 \%$ pertencem à agricultura familiar; a maioria são pequenos e médios produtores que produzem entre 100 a 300 litros de leite por dia e residem na propriedade, onde trabalham com sua família. A produção anual do município é de aproximadamente 52 milhões de litros, sendo que cinco milhões são destinados para produção de queijos (EMATER-MG, 2015). Possui rebanho bovino efetivo de 131.589 cabeças e vasta área de pastagem sendo 101.475 ha de pastagens formadas e 57.498 de pastagens naturais. O sistema produtivo predominante é de produção de leite a pasto com animais mestiços (azebuados) (IBGE,
2014). O município possui duas estações climáticas bem definidas, sendo uma denominada de período da seca (abril a setembro) e outra das águas (outubro a março), com pluviosidade média anual de $1.476 \mathrm{~mm}$ (Climate-Data.Org, 2015).

Objetivou-se, com este trabalho, realizar o diagnóstico de propriedades produtoras de leite, em regime de economia familiar, no que diz respeito a aspectos relacionados à cria de fêmeas bovinas leiteiras.

\section{Material e Métodos}

Foram avaliadas 12 propriedades, produtoras de leite em regime de economia familiar, localizadas na região Noroeste de Minas, no município de Presidente Olegário, na comunidade de Cachoeirinha/Boa Vista no período entre maio e junho de 2016.

Os produtores entrevistados foram selecionados aleatoriamente, independentemente do volume de leite comercializado ou do sistema de produção adotado. Para as entrevistas e diagnóstico utilizou-se um formulário semiestruturado, adaptado de Lopes et al. (2016). As questões foram divididas nos temas: cadastro do produtor e da propriedade, caracterização do rebanho e caracterização do sistema de produção de leite. Nesse último tópico incluia-se o sistema de produção, manejo nutricional, escrituração zootécnica, método de identificação dos animais e criação de bezerras. Na caracterização da cria das bezerras (nascimento até a desmama), foram elaboradas questões que abordaram os cuidados com a vaca no pré-parto e maternidade, cuidados com os recém-nascidos, dieta, infraestrutura, desmama, controle sanitário e principais doenças.

Os dados coletados foram cadastrados em planilhas do software Sphinx $^{\circledR}$ e realizado o agrupamento das respostas de acordo com sua categoria no formulário de diagnóstico obedecendo à classe a qual pertencia, ou seja, o tema a qual pertenciam: se sanidade, caracterização do rebanho etc., para facilitar a velocidade de transcrição, interpretação e aplicação de ferramentas de estatísticas.

Os resultados foram comparados por meio de análises descritivas, utilizando o aplicativo MS Excel $^{\circledR}$, e agrupados em tabelas, objetivando melhor apresentação, comparação e discussão, segundo Lopes et al. (2004). 


\section{Resultados e Discussão}

Em todas as propriedades avaliadas as vacas eram secas 60 dias antes do parto previsto ou em função de baixa produção de leite. Contudo, a maioria não possuía pasto ou piquete maternidade específico (Tabela 1). Em diagnóstico da pecuária leiteira no município de Barroso-MG, Marcatti Neto et al. (2007) constataram que havia a necessidade de adoção de pastos maternidade para as vacas pré-parto poderem receber suplementação alimentar adequada, principalmente durante a estação seca, para poderem entrar em lactação em melhores condições fisiológicas e sanitárias. É sabido que o bom manejo pré-parto é fundamental para a produção de leite na próxima lactação, assim como para redução do período de serviço e geração de crias mais saudáveis. Coelho (2009) destacou a importância da existência de piquete maternidade limpo e com boa cobertura vegetal para ajudar na prevenção de contaminação umbilical e regulação da temperatura corporal dos recém-nascidos. Segundo Campos (2012), o recolhimento da vaca para o piquete maternidade é fundamental para o fornecimento de dieta específica que garantirá bom desenvolvimento fetal no final da gestação e boa produção de colostro.

Tabela 1. Caracterização do manejo de vacas no pré-parto nas 12 propriedades estudadas do município de Presidente Olegário - MG, em maio e junho de 2016.

\begin{tabular}{cccc}
\hline Questão & \multirow{2}{*}{ Averiguação } & \multicolumn{2}{c}{ Quantidade } \\
\cline { 2 - 4 } & Total & \% \\
\hline \multirow{2}{*}{ Critério para secar uma vaca } & Produção & 2 & 16,67 \\
& Período antes do parto & 10 & 83,33 \\
\cline { 2 - 4 } São secas quantos dias antes do parto & 60 dias & 10 & 83,33 \\
Possui maternidade & Pela baixa produção de leite & 2 & 16,67 \\
\cline { 2 - 4 } & Sim & 2 & 16,67 \\
Tipo de maternidade & Não & 10 & 83,33 \\
\cline { 2 - 4 } Quantos dias antes do parto entram na & Piquete & 2 & 16,67 \\
maternidade & 30 dias & 1 & 8,33 \\
Após o parto, com quantos dias sai da & 5 dias & 1 & 8,33 \\
\cline { 2 - 4 } maternidade & 1 dia & 1 & 8,33 \\
\hline
\end{tabular}

O principal alimento volumoso das bezerras durante o período das águas foi o pasto, sendo a silagem de milho (Zea mays) o segundo mais usado nesse período. No período da seca, a silagem de milho foi o volumoso mais usado, seguido pelo pasto e também pelo capim elefante (Pennisetum purpureum) picado. Nenhuma propriedade oferecia feno. A maioria das propriedades oferecia ração concentrada para os animais, tanto nas águas quanto na seca, apesar de apenas duas propriedades ofertarem ração específica para bezerras. Sete propriedades ofereciam alguma suplementação mineral para as bezerras e, na dieta líquida, uma propriedade oferecia leite além da amamentação direta nas vacas, havendo ainda uma ofertando soro de leite (subproduto da fabricação do queijo) no período das águas (Tabela 2).

Coelho (2009) afirmou que para a atividade ser economicamente viável precisa-se dobrar o peso das bezerras ao nascimento nos primeiros 56 dias e para que essa meta seja atingida a definição de uma dieta completa e de bom manejo alimentar são fundamentais. Dessa forma, não apenas o fornecimento de alimentos suplementares deve ser considerado, mas também a forma e as quantidades em que devem ser fornecidos.

Na Tabela 3 podem ser observados aspectos gerais do manejo de bezerras recém-nascidas nas doze propriedades estudadas. Em todas as propriedades foi feita a cura do umbigo; porém, em onze delas ela foi feita apenas uma vez ao dia e, também na maioria, somente em um único dia. Todas faziam utilização de iodo, álcool iodado ou mata bicheira para cura do umbigo.

A maioria das propriedades não fazia higienização das tetas e nem avaliava a qualidade do colostro antes da ordenha ou amamentação. Para os recém-nascidos que não mamam o colostro nas mães, quatro das propriedades ofereciam até 2 litros, quatro de 2 a 4 litros; uma propriedade fornecia à vontade. A mamadeira foi utilizada para o fornecimento do colostro na maioria das propriedades nas situações em que os animais não mamavam espontaneamente nas vacas. A maioria 
só fornecia o colostro na ordenha da manhã seguinte, quando as vacas pariam à noite e o bezerro não mamava por si mesmo. Nenhuma propriedade possuía banco de colostro e o leite de transição era usado também para alimentar outros animais da fazenda, além das(os) bezerras(os) (Tabela 3).

Tabela 2. Caracterização dos alimentos fornecidos para bezerras até a desmama, nas 12 propriedades estudadas do município de Presidente Olegário - MG, em maio e junho de 2016.

\begin{tabular}{cccc}
\hline \multirow{2}{*}{ Questão } & Averiguação & Quantidade & Total \\
\cline { 2 - 3 } & Pasto & 9 & 75,00 \\
& Silagem de milho & 5 & 41,67 \\
Alimento época das águas - nascimento até & Ração leite & 5 & 41,67 \\
desmama & Ração bezerra & 2 & 16,67 \\
& Ração novilha & 1 & 8,33 \\
& Ração crescimento & 1 & 8,33 \\
& Mineral 2/1 & 3 & 25,00 \\
& Sal mineral & 3 & 25,00 \\
& Mineral recria & 1 & 8,33 \\
& Leite & 8,33 \\
Alimentos na época da seca - nascimento até & Soro do leite & 1 & 8,33 \\
desmama & Pasto & 6 & 50,00 \\
& Silagem de milho & 7 & 58,33 \\
& Capim elefante & 1 & 8,33 \\
& Ração leite & 6 & 50,00 \\
& Ração bezerra & 2 & 16,67 \\
& Ração novilha & 1 & 8,33 \\
& Mineral 2/1 & 33,33
\end{tabular}

A falta de banco de colostro demonstra falha básica no manejo da criação de bezerras nas propriedades avaliadas, uma vez que em situações em que ocorra morte de vacas ao parto ou em que as mesmas produzam colostro em quantidade ou qualidade inferior, as bezerras correrão o risco de não receberem imunidade contra os patógenos ambientais, aumentando os índices de morbidade e mortalidade na fase de cria. Silva e Hickmann (2011) ressaltaram a importância para o fornecimento de colostro nas primeiras 24 horas e os cuidados com a cura do umbigo na prevenção de doenças. Abordando os desafios na criação e saúde de bezerros, Coelho (2009) recomendou o fornecimento de colostro de boa qualidade e em quantidade adequada ao tamanho do recémnascido, bem como a utilização de tintura de iodo na cura do umbigo imediatamente após o nascimento, para prevenir a contaminação do coto umbilical e conferir satisfatória transferência de imunidade passiva, fundamental para a sobrevivência dos animais.

$\mathrm{O}$ leite era fornecido para as bezerras e bezerros de forma natural em 10 das propriedades e nenhum produtor utilizava sucedâneos. Para os animais até os 30 dias, em três das propriedades a amamentação era com uma teta, três deixavam uma sobra no úbere, duas não controlavam o fornecimento e o restante das propriedades fornecia de 3 a 6 litros diários. Para os animais entre 30 e 60 dias, dois terços das propriedades utilizavam apenas repasse após a ordenha, para a amamentação e o restante fornecia de 3 a 4 litros. Entre 60 e 90 dias a mesma proporção oferecia apenas o repasse após a ordenha, três propriedades até 2 litros e em uma não houve fornecimento. Em todas as propriedades a amamentação ou aleitamento era feita logo após a ordenha e os animais também recebiam leite de vacas com tratamento de antibióticos. Observou-se que seis proprietários relataram que quando o leite era ofertado, esse aleitamento era feito com o leite em temperatura ambiente (Tabela 4).

Segundo Moran (2012), a temperatura da dieta líquida pode não influenciar no desenvolvimento dos animais se a temperatura ambiente não for baixa e eles estiverem saudáveis. Contudo, a temperatura de $39^{\circ} \mathrm{C}$ seria a mais comum para aleitamento e parece estimular o consumo e facilitar a digestibilidade do alimento. 
Rodrigues et al. (2002) ressaltaram que a temperatura da dieta líquida próxima à corporal é importante também como fator de estímulo para a ocorrência do reflexo de fechamento da goteira esofágica. $\mathrm{O}$ fornecimento de água pela primeira vez, na maioria das propriedades, era feito a partir do primeiro dia de vida. Para higienização de utensílios somente uma propriedade utilizava água e cloro. Todas as demais usavam apenas água e sabão (Tabela 4).

Tabela 3. Caracterização do manejo de bezerras recém-nascidas nas 12 propriedades estudadas do município de Presidente Olegário - MG, em maio e junho de 2016.

\begin{tabular}{|c|c|c|c|}
\hline \multirow{2}{*}{ Questão } & \multirow{2}{*}{ Averiguação } & \multicolumn{2}{|c|}{ Quantidade } \\
\hline & & Total & $\%$ \\
\hline Realiza curativo do umbigo & Sim & 12 & 100,00 \\
\hline \multirow{3}{*}{ Quantas vezes por dias por dia é feito o curativo } & $1 \mathrm{vez}$ & 11 & 91,67 \\
\hline & 2 vezes & 1 & 8,33 \\
\hline & $1 \mathrm{dia}$ & 7 & 58,33 \\
\hline \multirow{3}{*}{ Quantos dias o umbigo é curado } & 2 a 3 dias & 2 & 16,67 \\
\hline & Mais de 3 dias & 2 & 8,33 \\
\hline & Até cair & 1 & 8,33 \\
\hline \multirow{4}{*}{ No manejo de cura de umbigo realiza-se } & Corte & 2 & 16,67 \\
\hline & Queima & 2 & 16,67 \\
\hline & Corte e queima & 8 & 66,67 \\
\hline & Mata bicheira & 2 & 16,67 \\
\hline \multirow{2}{*}{ O que usa para curar o umbigo } & Iodo $10 \%$ & 9 & 75,00 \\
\hline & Álcool iodado 5\% & 1 & 8,33 \\
\hline \multirow{2}{*}{$\begin{array}{l}\text { Realiza higienização das tetas antes da ordenha do } \\
\text { colostro }\end{array}$} & Sim & 3 & 25,00 \\
\hline & Não & 9 & 75,00 \\
\hline Caso sim, como é feita a higienização das tetas & Lava com água, seca e faz pré-dipping & 3 & 25,00 \\
\hline \multirow{3}{*}{$\begin{array}{l}\text { Quanto tempo após o nascimento a(o) bezerra(o) } \\
\text { recebe colostro }\end{array}$} & 2 horas & 10 & 83,33 \\
\hline & 6 horas & 1 & 8,33 \\
\hline & Na próxima ordenha & 1 & 8,33 \\
\hline \multirow{3}{*}{$\begin{array}{l}\text { Bezerras(os) que não mamam nas mães, quantos } \\
\text { litros de colostro bebem na primeira mamada }\end{array}$} & Até 2 litros & 4 & 33,33 \\
\hline & 2 a 4 litros & 4 & 33,33 \\
\hline & A vontade & 1 & 8,33 \\
\hline \multirow{3}{*}{$\begin{array}{c}\text { Se não mamar sozinho, fornecimento de colostro } \\
\text { é através de }\end{array}$} & Mamadeira & 10 & 83,33 \\
\hline & Outros & 2 & 16,67 \\
\hline & Até 2 litros & 2 & 16,67 \\
\hline \multirow[t]{2}{*}{ Quantos litros de colostro são fornecidos } & 2 a 4 litros & 5 & 41,67 \\
\hline & A vontade & 4 & 33,33 \\
\hline \multirow{2}{*}{ Vaca pare à noite, quando é fornecido o colostro } & Na ordenha da manhã & 11 & 91,67 \\
\hline & Mama sozinho & 1 & 8,33 \\
\hline \multirow{2}{*}{ Avalia a qualidade do colostro } & Sim & 3 & 25,00 \\
\hline & Não & 9 & 75,00 \\
\hline \multirow{2}{*}{$\begin{array}{c}\text { Avaliação do colostro é usada como critério de } \\
\text { colostragem }\end{array}$} & Sim & 2 & 16,67 \\
\hline & Não & 1 & 8,33 \\
\hline \multirow{2}{*}{ O que é feito com o leite de transição } & Usado para o bezerro & 7 & 58,33 \\
\hline & Usado para outros animais & 5 & 41,67 \\
\hline Existe banco de colostro na propriedade & Não & 12 & 100,00 \\
\hline
\end{tabular}

Um dos problemas da criação de bezerras "ao pé das vacas" é a falta de controle da quantidade de leite diariamente ingerida pelos animais que, normalmente, é baixa. No presente diagnóstico, em oito das 12 propriedades não existia o controle sobre a quantidade ingerida. Coelho (2009) ressaltou que o quantidades de leite fixadas em até $4 \mathrm{~kg}$ dia $^{-1}$ normalmente são restritivas ao crescimento e sanidade das bezerras, principalmente nos 30 primeiros dias de vida.
Na Tabela 5 pode-se observar que a maioria das propriedades fazia também a criação de machos e a alimentação dos bezerros não diferia da alimentação das fêmeas. $\mathrm{O}$ fornecimento de concentrado na fase de cria era feito a partir do primeiro dia em quatro das propriedades, sendo que mais do que a metade das propriedades não fazia controle da quantidade do fornecimento. Contudo, a maioria dos produtores tinham consciência que forneciam pouca quantidade de concentrado. Todas 
as propriedades forneciam forragem para as bezerras e em metade esse fornecimento se iniciava a partir do primeiro dia de vida. A criação das bezerras, em oito das propriedades, era feita em piquetes de forma coletiva, apenas uma utilizava baia individual com abrigo sem contatos entre animais e também uma adotava baia individual sem abrigo. Duas utilizavam instalações comuns às vacas. A maioria dos bezerreiros se situava abaixo do curral o que pode representar aumento nos problemas sanitários na cria; e o sol incidia diretamente em pelo menos 10 dos bezerreiros. O sombreamento dos bezerreiros, em nove das propriedades, era natural e em uma não havia sombra A criação de bezerros machos provenientes de cruzamento de vacas leiteiras com bois de raças de corte é prática comum na pecuária leiteira brasileira, principalmente nas pequenas propriedades familiares.

Tabela 4. Caracterização da alimentação com dieta líquida de bezerras nas 12 propriedades estudadas do município de Presidente Olegário - MG, em maio e junho de 2016.

\begin{tabular}{|c|c|c|c|}
\hline \multirow{2}{*}{ Questão } & \multirow{2}{*}{ Averiguação } & \multicolumn{2}{|c|}{ Quantidade } \\
\hline & & Total & $\%$ \\
\hline \multirow{2}{*}{ Como é oferecido o leite para a(o) bezerra(o) } & Natural & 10 & 83,33 \\
\hline & Artificial com mamadeira & 2 & 16,67 \\
\hline \multirow[t]{3}{*}{ Usa sucedâneo } & Não & 12 & 100,00 \\
\hline & 1 teta & 3 & 25,00 \\
\hline & Não controla & 2 & 16,67 \\
\hline \multirow{3}{*}{ Quantos litros de leite são fornecidos até 30 dias } & 3 a 4 litros & 1 & 8,33 \\
\hline & 5 a 6 litros & 3 & 25,00 \\
\hline & Deixa um pouco no úbere & 3 & 25,00 \\
\hline \multirow{3}{*}{ Entre 30 e 60 dias } & Repasse após ordenha & 8 & 66,67 \\
\hline & 3 a 4 litros & 4 & 33,33 \\
\hline & Repasse após ordenha & 8 & 66,66 \\
\hline \multirow[t]{2}{*}{ Entre 60 e 90 dias } & 2 litros & 3 & 25,00 \\
\hline & 0 & 1 & 8,33 \\
\hline Qual a temperatura do leite fornecido & Ambiente & 6 & 50,00 \\
\hline O aleitamento é feito logo após a ordenha & Sim & 12 & 100,00 \\
\hline Existe constância no horário de fornecimento & Sim & 12 & 100,00 \\
\hline \multirow{2}{*}{ Quem fornece o leite para as(os) bezerros(as) } & Ordenhador & 3 & 25,00 \\
\hline & Outro & 4 & 33,33 \\
\hline \multirow{2}{*}{ Como os utensílios são lavados } & Água e sabão & 11 & 91,67 \\
\hline & Água e cloro & 1 & 8,33 \\
\hline Recebe leite de vacas com antibióticos & Sim & 12 & 100,00 \\
\hline \multirow{2}{*}{ Com quantos dias recebe água pela primeira vez } & A partir do primeiro dia & 10 & 83,33 \\
\hline & 8 a 10 dias & 2 & 16,67 \\
\hline
\end{tabular}

Marcatti Neto et al. (2007) destacaram essa característica na pecuária leiteira familiar no Estado de Minas Gerais, ressaltando a importância dos animais mestiços para a produção familiar. Contudo, também observaram que a prática dos cruzamentos europeu x zebu pode ser prejudicial aos sistemas de produção de leite onde se dispensa grande parte dos recursos na cria e recria de animais que não produzirão leite (machos) ou que o produzirão em quantidade inviável (fêmeas de reposição sem aptidão leiteira). A cria e recria de bezerros em sistemas familiares normalmente não é devidamente acompanhada de criterioso estudo de viabilidade e comumente expressa a falta de especialização dos produtores brasileiros na pecuária de leite.
Como os bezerros são criados junto com as bezerras, eles também podem ser potenciais fontes de contágio de doenças para as fêmeas, uma vez que, normalmente, os machos, por não apresentarem o mesmo valor comercial das fêmeas nos rebanhos leiteiros, são mais susceptíveis a problemas na fase de cria por terem pouca ou nenhuma ingestão de colostro, o que aumenta sobremaneira as taxas de morbidade e mortalidade entre eles (Almeida Júnior et al., 2008).

Silva e Hickmann (2011) destacaram a importância do fornecimento de alimentos concentrados visando ao precoce desenvolvimento ruminal e da criação de bezerras em ambiente adequado, recomendando preferencialmente ração balanceada à vontade e abrigos individuais até à 
desmama ou desaleitamento. Quando não há essa possibilidade em função do sistema de criação com bezerros ao pé das vacas, recomendaram a adoção de piquetes específicos para os animais em função da sua faixa etária para a prevenção de problemas sanitários.

Tabela 5. Caracterização do manejo e alimentação com alimentos sólidos de bezerras nas 12 propriedades estudadas do município de Presidente Olegário - MG, em maio e junho de 2016.

\begin{tabular}{|c|c|c|c|}
\hline \multirow{2}{*}{ Questão } & \multirow{2}{*}{ Averiguação } & \multicolumn{2}{|c|}{ Quantidade } \\
\hline & & Total & $\%$ \\
\hline \multirow{2}{*}{ Faz criação de bezerros machos } & Sim & 10 & 83,33 \\
\hline & Não & 2 & 16,67 \\
\hline Alimentação do macho difere da fêmea & Não & 10 & 100,00 \\
\hline Com quantos dias a(o) bezerra(o) recebe & A partir do primeiro dia & 4 & 33,33 \\
\hline concentrado pela primeira vez & Outro & 5 & 41,67 \\
\hline \multirow{2}{*}{$\begin{array}{c}\text { Mede a quantidade de ração que fornece às(aos) } \\
\text { bezerras(os) }\end{array}$} & Sim & 2 & 16,67 \\
\hline & Não & 7 & 58,33 \\
\hline \multirow{3}{*}{$\begin{array}{l}\text { Quantidade de concentrado oferecida às(aos) } \\
\text { bezerras(os) }\end{array}$} & Não fornece & 3 & 25,00 \\
\hline & Menos de $0,5 \mathrm{~kg}$ & 6 & 50,00 \\
\hline & 0,5 a $2,0 \mathrm{Kg}$ & 3 & 25,00 \\
\hline \multirow{2}{*}{ Fornece forragem para as(os) bezerras(os) } & Sim & 12 & 100,00 \\
\hline & A partir do primeiro dia & 6 & 50,00 \\
\hline \multirow{3}{*}{$\begin{array}{l}\text { Com quantos dias a bezerra recebe forragem pela } \\
\text { primeira vez }\end{array}$} & 60 dias & 3 & 25,00 \\
\hline & 8 dias & 2 & 16,67 \\
\hline & Fica sempre no pasto & 1 & 8,33 \\
\hline \multirow{4}{*}{ Instalação, bezerras em amamentação } & Baia individual com abrigo & 1 & 8,33 \\
\hline & Piquete & 8 & 66,67 \\
\hline & Instalacoes das vacas & 2 & 16,67 \\
\hline & Individual sem abrigo & 1 & 8,33 \\
\hline \multirow{2}{*}{ Tipo de piso da instalação } & Pasto & 6 & 50,00 \\
\hline & Terra & 1 & 8,33 \\
\hline \multirow[t]{2}{*}{ Quanto tempo abrigo é trocado de lugar } & Nunca & 1 & 8,33 \\
\hline & Sombrite & 2 & 16,67 \\
\hline \multirow[t]{2}{*}{ Tem sombra na instalação } & Natural & 9 & 75,00 \\
\hline & Não tem & 1 & 8,33 \\
\hline \multirow{3}{*}{ Quantos animais por instalação } & 1 & 2 & 16,67 \\
\hline & Coletivo & 10 & 83,33 \\
\hline & Abaixo do curral & 7 & 58,33 \\
\hline \multirow[t]{2}{*}{ Qual a posição do bezerreiro } & Ao lado do curral & 3 & 25,00 \\
\hline & Dentro do curral & 1 & 8,33 \\
\hline \multirow{2}{*}{$\begin{array}{l}\text { Quando saem do abrigo individual, quanto tempo } \\
\text { depois coloca outro }\end{array}$} & Imediatamente & 1 & 8,33 \\
\hline & Outro & 1 & 8,33 \\
\hline \multirow{2}{*}{ Bate sol no bezerreiro } & Sim & 10 & 83,33 \\
\hline & Não & 1 & 8,33 \\
\hline
\end{tabular}

Almeida Júnior et al. (2008) ressaltaram que as bezerras devem iniciar o mais cedo possível o consumo alimentos concentrados, uma vez que os ácidos graxos provenientes da fermentação ruminal são primordiais para o desenvolvimento do rúmen e da flora microbiana e, ainda, para a transição da fase de pré-ruminante a ruminante, permitindo que o animal seja desmamado ou desaleitado em menos tempo. Outro aspecto importante é que o custo da ração concentrada para bezerras, embora devesse ser composta de ingredientes nobres, com baixos teores de fibra e elevados níveis energéticos, quase sempre é menor do que o custo do leite ou sucedâneo utilizado no aleitamento. Além disso, a partir do momento em que os animais apresentam satisfatório consumo de concentrados, o alimento líquido (leite ou sucedâneo) passa a ter menos importância na ingestão de matéria seca e no desempenho animal, o que permite a desmama ou desaleitamento dos bezerros e bezerras e a consequente diminuição dos custos na fase de cria de propriedades produtoras de leite.

Conforme se observa na Tabela 6 , a descorna, na maioria das propriedades, era feita aos 30 dias ou mais, e o método utilizado em todas as propriedades era o ferro quente. Apenas em uma propriedade era feita a remoção de tetas extranu- 
merárias. A identificação dos animais, em metade das propriedades era feita utilizando apenas o nome da mãe e somente quatro propriedades utilizavam o brinco como identificação. Apenas um pecuarista realizava pesagem das bezerras ao nascimento e também para controle de peso à desmama. Somente três propriedades efetuavam a desmama entre $60 \mathrm{e}$ 90 dias, sendo que o principal critério para a desmama ou desaleitamento era a idade da bezerra, seguido pelo critério secagem da vaca. $\mathrm{O}$ monitoramento do desenvolvimento inicial das bezerras é fundamental para a identificação precoce de eventuais problemas sanitários e também para a seleção de animais com maior aptidão à produção leiteira (Oliveira e Nogueira,
2006), além de auxiliar na escolha do momento certo para a desmama, pois quanto mais tarde essa for realizada, maior será o consumo de leite pelos animais e menor será a quantidade disponível para a venda e, por isso, a desmama precoce é prática recomendável. No entanto, segundo Lizieire et al. (2002), dois aspectos devem ser levados em consideração para a adoção dessa prática: o custo da criação e o desenvolvimento do animal. O primeiro é o principal objetivo, mas, se o animal não estiver com o rúmen bem desenvolvido para o aproveitamento de alimentos sólidos, o lucro proveniente da venda do leite, que deveria ter sido fornecido ao mesmo, poderá ser anulado com o aumento dos índices de morbidade e mortalidade.

Tabela 6. Caracterização do manejo de bezerras nas 12 propriedades estudadas do município de Presidente Olegário, MG, em maio e junho de 2016.

\begin{tabular}{|c|c|c|c|}
\hline \multirow{2}{*}{ Questão } & \multirow{2}{*}{ Averiguação } & \multicolumn{2}{|c|}{ Quantidade } \\
\hline & & Total & $\%$ \\
\hline \multirow{2}{*}{ Quando é feita a descorna } & 30 dias ou mais & 7 & 58,33 \\
\hline & Varia & 5 & 41,67 \\
\hline Qual o método é utilizado & Ferro quente & 12 & 100,00 \\
\hline \multirow{2}{*}{ Remove as tetas extranumerárias } & Sim & 1 & 8,33 \\
\hline & Não & 11 & 91,67 \\
\hline \multirow[t]{2}{*}{ Caso sim, como é feita a remoção } & Corta com tesoura e queima & 1 & 8,33 \\
\hline & Ferro quente & 1 & 8,33 \\
\hline \multirow{3}{*}{ Identificação da(o) bezerra(o) } & Brinco & 4 & 33,33 \\
\hline & Nome próprio & 2 & 16,67 \\
\hline & Nome da mãe & 6 & 50,00 \\
\hline \multirow{2}{*}{ Quando a identificação é realizada } & No dia do nascimento & 4 & 33,33 \\
\hline & outro & 8 & 66,67 \\
\hline \multirow{2}{*}{ Realiza pesagem das bezerras } & Sim & 1 & 8,33 \\
\hline & Não & 11 & 91,67 \\
\hline Caso sim quando ocorre & Ao nascimento & 1 & 8,33 \\
\hline Caso sim, qual método utilizado & Fita de pesagem & 1 & 8,33 \\
\hline Com qual objetivo & Controlar peso desmama & 1 & 8,33 \\
\hline \multirow{2}{*}{$\begin{array}{l}\text { Existe outros métodos de acompanhamento de } \\
\text { crescimento das bezerras? }\end{array}$} & Sim & 3 & 25,00 \\
\hline & Não & 9 & 75,00 \\
\hline \multirow{2}{*}{ Caso sim, quais os métodos } & Escore de condição corporal & 2 & 16,67 \\
\hline & Estimativa de peso & 1 & 8,33 \\
\hline \multirow{4}{*}{ Qual o critério de desmama/desaleitamento } & Peso & 1 & 8,33 \\
\hline & Idade & 6 & 50,00 \\
\hline & Secagem da mãe & 5 & 41,67 \\
\hline & 60 dias & 1 & 8,33 \\
\hline \multirow[t]{2}{*}{ Com qual idade a bezerra é desmamada/desaleitada } & 61 a 90 dias & 2 & 16,67 \\
\hline & Outro & 9 & 75,00 \\
\hline \multirow{4}{*}{ Com qual idade o bezerro é desmamado/desaleitado } & 60 dias & 1 & 8,33 \\
\hline & 61 a 90 dias & 2 & 16,67 \\
\hline & Secagem vaca (6 a 10 meses) & 8 & 66,67 \\
\hline & Faz doação & 1 & 8,33 \\
\hline
\end{tabular}

Com relação ao controle da sanidade das bezerras, apenas uma propriedade adotava calendário sanitário específico. Contudo, todos os proprietários realizavam a vacinação dos animais contra brucelose, raiva e febre aftosa, metade contra manqueira e outros cinco contra clostridioses diversas. A maioria das propriedades tinha problemas com carrapatos, apresentando taxas de infestações médias a altas (Tabela 7). 
Tabela 7. Caracterização do manejo sanitário de bezerras nas 12 propriedades estudadas do município de Presidente Olegário - MG, em maio e junho de 2016.

\begin{tabular}{|c|c|c|c|}
\hline \multirow{2}{*}{ Questão } & \multirow{2}{*}{ Averiguação } & \multicolumn{2}{|c|}{ Quantidade } \\
\hline & & Total & $\%$ \\
\hline \multirow{3}{*}{ Existe um calendário sanitário? } & Sim & 1 & 8,33 \\
\hline & Não & 11 & 91,67 \\
\hline & Brucelose, Raiva, Febre aftosa & 12 & 100,00 \\
\hline \multirow{2}{*}{ Quais vacinas são aplicadas regularmente } & Clostridiose (manqueira) & 6 & 50,00 \\
\hline & Clostridioses diversas & 5 & 41,67 \\
\hline \multirow{3}{*}{$\begin{array}{c}\text { Taxa de infestação de carrapatos em } \\
\text { Bezerras }\end{array}$} & Baixa & 2 & 16,67 \\
\hline & Média & 5 & 41,67 \\
\hline & Alta & 5 & 41,67 \\
\hline \multirow{3}{*}{ Critério para controle de carrapato } & Grau de infestação & 11 & 91,67 \\
\hline & De acordo com a bula & 1 & 8,33 \\
\hline & Baixa & 4 & 33,33 \\
\hline \multirow{2}{*}{ Taxa de infestação de bernes em bezerras } & Média & 4 & 33,33 \\
\hline & Alta & 4 & 33,33 \\
\hline \multirow{2}{*}{$\begin{array}{c}\text { Taxa de infestação de mosca do chifre em } \\
\text { bezerras }\end{array}$} & Média & 5 & 41,60 \\
\hline & Alta & 7 & 58,33 \\
\hline \multirow{3}{*}{$\begin{array}{c}\text { Taxa de infestação de mosca doméstica em } \\
\text { bezerras }\end{array}$} & Baixa & 1 & 8,33 \\
\hline & Média & 5 & 41,67 \\
\hline & Alta & 6 & 50,00 \\
\hline \multirow{2}{*}{ É feita vermifugação } & Bezerras mamando & 12 & 100,00 \\
\hline & Bezerras desmamadas & 10 & 83,33 \\
\hline \multirow{2}{*}{ Critério adotado para tratamento } & Infestação & 6 & 50,00 \\
\hline & Outros & 4 & 33,33 \\
\hline \multirow[t]{2}{*}{ Realiza OPG } & Não & 12 & 100,00 \\
\hline & Diarreia & 12 & 100,00 \\
\hline \multirow{2}{*}{ Quais doenças mais ocorrem nas bezerras } & Tristeza parasitária & 10 & 83,33 \\
\hline & Pneumonia & 9 & 75,00 \\
\hline \multirow{2}{*}{ Bezerras doentes são separadas das sadias? } & Sim & 2 & 16,67 \\
\hline & Não & 10 & 83,33 \\
\hline \multirow{2}{*}{ Qual idade ocorre diarreia } & Até 30 dias & 11 & 91,67 \\
\hline & Acima de 30 dias & 1 & 8,33 \\
\hline Qual o tratamento & Antibiótico & 12 & 100,00 \\
\hline \multirow{2}{*}{ Qual idade ocorre a pneumonia } & Até 30 dias & 8 & 66,67 \\
\hline & Mais de 30 dias & 1 & 8,33 \\
\hline Qual o tratamento & Antibiótico & 9 & 75,00 \\
\hline \multirow{2}{*}{ Qual idade ocorre tristeza parasitária } & $30-60$ dias & 2 & 16,67 \\
\hline & $60-120$ dias & 8 & 66,67 \\
\hline \multirow{2}{*}{ Qual o tratamento } & Hemoparasiticida+antibiótico & 9 & 75,00 \\
\hline & Apenas hemoparasiticida & 1 & 8,33 \\
\hline \multirow{2}{*}{ Há bezerras com problema de umbigo? } & Sim & 4 & 33,33 \\
\hline & Não & 8 & 66,67 \\
\hline \multirow{2}{*}{ Quando há problema, realiza tratamento? } & Sim & 9 & 75,00 \\
\hline & Não & 1 & 8,33 \\
\hline
\end{tabular}

O critério para controle de carrapatos utilizado em 11 das propriedades foi o grau de infestação e em todas elas a taxa de infestação de moscas e carrapatos foi predominantemente, de média a alta. Nenhuma propriedade realizava o teste OPG (ovos por grama de fezes). Apenas dois produtores separavam as bezerras doentes dos animais sadios; e em todas as propriedades houve ocorrência de diarreia, principalmente nos primeiros 30 dias de vida. Também houve forte prevalência de pneumonia nas propriedades no pri- meiro mês de vida das bezerras. Apesar do gado ser mestiço, em 10 das propriedades houve ocorrência de tristeza parasitária e, em todas, as bezerras doentes eram tratadas. Para o tratamento de diarreia e pneumonia, o medicamento utilizado foi antibiótico; e para a tristeza parasitária foi hemoparasiticida, na maioria das vezes, associado a antibiótico. Em quatro das propriedades houve bezerros com problemas no umbigo (Tabela 7).

Em seu diagnóstico, Marcatti Neto et al. (2007) averiguaram que $97,5 \%$ dos produtores de 
leite no município de Barroso, MG, vacinavam contra febre aftosa e raiva e outros $76,9 \%$ vacinavam contra brucelose. Em levantamento similar feito com produtores de leite no Agreste de Pernambuco, Monteiro et al. (2007) observaram que $95 \%$ dos produtores vacinavam contra febre aftosa e $56 \%$ contra brucelose. Observou-se nesses levantamentos que apesar da vacinação contra febre aftosa ser obrigatória, a mesma não foi praticada por todos os pecuaristas avaliados nesses estudos. No que diz respeito aos problemas relacionados ao trato digestório, Coelho (2009) destacou que as diarreias são a causa mais frequente de mortalidade dos bezerros e ocorrem principalmente nas duas primeiras semanas de vida dos animais. Segundo essa autora, até 30 dias de idade, os maiores desafios para os bezerros são as diarreias e os problemas respiratórios, enquanto de 30 a 120 dias, na maioria das vezes, são a tristeza parasitária e os problemas respiratórios.

\section{Conclusão}

A fase de cria nas propriedades leiteiras familiares do município de Presidente Olegário apresenta diversas deficiências que se iniciam já no manejo das vacas no pré-parto e perpassam todo o período compreendido até o desmame ou desaleitamento das bezerras.

A ausência de instalações adequadas à criação dos animais bem como a falta de critérios técnicos na alimentação pode estar contribuindo significativamente para o aumento na ocorrência de diversos problemas sanitários relatados nos plantéis avaliados.

Não há adoção de protocolo sanitário específico para as bezerras sendo que a falta de cuidados profiláticos recomendáveis, além de expor os animais a maiores incidências de doenças, desvia o foco da atenção e também dos recursos dos produtores para o tratamento de animais doentes ao invés da prevenção das mesmas. As possibilidades de viabilização técnica e econômica da pecuária familiar se tornam menores face às limitações observadas na fase de cria.

\section{Conflito de Interesse}

Os autores declaram não existir conflito de interesse.

\section{Comitê de Ética}

A caracterização foi obtida de dados provenientes de propriedades assistidas por progra- ma da EMATER-MG, não sujeita a avaliação de comitê de ética. As propriedades e produtores foram mantidos anônimos.

\section{Agradecimentos}

Os autores agradecem à EMATER - MG, por ter possibilitado a realização desta pesquisa, e ao CNPq pela concessão de bolsa de produtividade ao terceiro autor.

\section{Referências}

Almeida Júnior, G.A.; Costa, C.; Carvalho, S.M.R.; Panichi, A.; Persichetti Júnior, P. Desempenho de bezerros holandeses alimentados até o desaleitamento com silagem de grãos úmidos ou grãos secos de milho ou sorgo. Revista Brasileira de Zootecnia, 37(1): 140-147, 2008.

Campos, O.F. Bezerras: o futuro da propriedade. In Almeida Júnior, G.A.; Stradiotti Júnior, D.; Silva, E.C.G.; Andrade, M.A.N.; Almeida, M.I.V.; Cóser, A.C. Avanços tecnológicos na bovinocultura de leite. Alegre: CAUFES, 2012. p.142-156.

Climate-Data.Org. Dados climáticos para cidades mundiais. Gráfico climático. Disponível em: <http://pt.climatedata.org/location/176030/>. Acesso em: 6 dez. 2015.

Coelho, S.G. Desafios na criação e saúde de bezerros. Ciência Animal Brasileira, 10(1): 1-16, 2009.

Empresa de Assistência Técnica e Extensão Rural do Estado de Minas Gerais - EMATER-MG. Sistema safra pecuária. Presidente Olegário: EMATER-MG, 2015.

Instituto Brasileiro de Geografia e Estatística IBGE. Produção da pecuária municipal. Rio de Janeiro: IBGE, 2014. Disponível em: <http://www.cidades.ibge.gov.br/xtras/temas. php?lang $=\&$ codmun $=315340 \&$ idtema $=147 \&$ search $=$ minas-gerais|presidente-olegario|pecuaria2014>. Acesso em: 6 dez. 2015.

Lizieire, R.S.; Cunha, D.N.F.V.; Martuscello, J.A.; Campos, O.F. Fornecimento de volumosos para bezerros pré-ruminantes. Ciência Rural, 32(5): 835-840, 2002.

Lopes, M.A.; Lima, A.L.R.; Carvalho, F.M.; Reis, R.P.; Santos, I.C.; Saraiva, F.H. Controle gerencial e estudo da rentabilidade de sistemas de produção de leite na região de Lavras 
(MG). Ciência e Agrotecnologia, 28(4): 883892, 2004.

Lopes, M.A.; Reis, E.M.B.; Ferrazza, R.A. Formulário de diagnóstico da propriedade leiteira. Lavras: UFLA, 19 p. 2016.

Lopes, M.A.; Santos, G. Custos de produção de fêmeas bovinas leiteiras do nascimento ao primeiro parto. Ciência Animal Brasileira, 15(1): 11-19, 2014.

Marcatti Neto, A.; Gonçalves Filho, A.F.; Godoy, M.; Amaral, R.; Azevedo, N.A.; Silva, J.B. Diagnóstico da pecuária leiteira do município de Barroso. Belo Horizonte: EPAMIG, 24p. 2007.

Monteiro, A.A.; Tamanini, R.; Silva, L.C.C.; Mattos, M.R.; Magnani, D.F.; Ovidio, L.; Nero, L.A.; Barros, M.A.F.; Pires, E.M.F.; Paquereau, B.P.D.; Beloti, V. Características da produção leiteira da região do agreste do estado de Pernambuco, Brasil. Semina: Ciências Agrárias, 28(4): 665-674, 2007.
Moran, J. Milk feeding of calves. In:

Rearing young stock on tropical dairy farms in Asia. Victoria: CSIRO, 2012. p.91108.

Oliveira, D.J.C.; Nogueira, G.P. Curvas de crescimento de bezerros da raça girolando. Arquivos de Ciências Veterinárias e Zoologia da UNIPAR, 9(1): 3-8, 2006.

Rodrigues, R.R.; Lucci, C.S.; Rodrigues, P.H.M. Alimentação de bezerros ruminantes com dieta sólida ou líquida, via goteira esofageana: formação da goteira e escape ruminal. Revista Brasileira de Zootecnia, 31(6): 2364-2372, 2002.

Silva, K.T.; Hickmann, C. Criação da bezerra leiteira. Belo Horizonte: Circular Técnica $\mathrm{n}^{\circ}$ : 135, maio 2011. Disponível em <http://www.epamig.br/index.php?option=co $\mathrm{m}_{\text {_ }} \quad$ docman\&task $=$ doc_download\&gid= 1679>. Acesso em: 7 dez. 2015. 